\title{
贵州凉风洞大气降水-土壤水-滴水的 $\delta^{18} \mathbf{O}$ 信号传递 及其意义
}

罗维均, 王世杰 ${ }^{*}$

中国科学院地球化学研究所环境地球化学国家重点实验室, 贵阳 550002

*联系人: E-mail: wangshijie@vip.skleg.cn

2008-04-21 收稿, 2008-05-30 接受

国家重点基础研究发展计划项目(批准号: 2006CB403200)、中国科学院知识创新工程方向性项目(批准号: KZCX2-YW-306)、创新团队国际 合作伙伴计划和国家自然科学基金项目(批准号: 90202003)资助

摘要 通过对贵州荔波凉风洞(LFD)大气降水、土壤水、土壤气、洞穴滴水以及滴水对应 的现代化学沉积物氧(氢)同位素组成的系统监测, 发现 LFD 土壤水和滴水主要来源于当 地大气降水; 3 种水 (大气降水、土壤水和滴水)氧同位素值的变化幅度在年内依次减小, 分 别在 $0 \sim-10 \%,-2 \%$ $-9 \%$ 和 $-6 \%$ $~-8 \%$ 之间; 3 种水氧同位素值之间存在大致协调同步的 季节变化规律: 雨季偏轻, 旱季偏重; 地表蒸发作用导致滴水氧同位素年算术平均值相对 于大气降水值偏重约 $0.3 \%$ 以上. 计算结果验证了 LFD 系统中洞穴次生化学沉积物形成过

关键词

贵州凉风洞

洞穴滴水

氧同位素

洞穴次生化学沉积物

古气候 程基本达到了氧同位素平衡, 利用洞穴沉积物氧同位素值恢复和重建古气温和降水量是 可行的, 但应注意研究区地表蒸发作用对氧同位素值的调节作用.

早在 20 世纪 60 年代, Hendy和 Wilson ${ }^{[1]}$ 与 Duplessey等人 ${ }^{[2]}$ 就分别在新西兰和法国率先利用石 笋的 $\delta^{18} \mathrm{O}$ 研究古气候. 尔后, Hendy ${ }^{[3]}$ 对利用石笋氧 同位素重建古气候的方法作了系统论述，使该领域 的工作成为(古)全球变化研究的热点 ${ }^{[4 \sim 15]}$. 尤其近年 来, 在我国南方地区，利用石笋稳定氧同位素替代指 标反映古气候变化的研究获得了重要进展 ${ }^{[5,6,10,12 ~ 15]}$. 但随着对洞穴系统现代过程监测工作的开展, 也出 现了一些新的问题. 如李彬等人 ${ }^{[16]}$ 通过对桂林地区 盘龙洞洞穴滴水与现代碳酸盐沉积物氧同位素研究 后发现, 沉积物的 $\delta^{18} \mathrm{O}$ 值与年均气温之间并不存在 着简单的一一对应关系. 在水动力条件不好、沉积十 分缓慢的条件下, 碳酸盐沉积物的氧同位素将极大 地偏离当地的年均气温. Bar-Matthews等人 ${ }^{[17]}$ 通过对 地中海沿岸一个洞穴系统的研究也获得了相似的结 论. 这些都说明洞穴系统中氧同位素等气候替代指 标的形成是个相当复杂的过程, 需要进一步的工作 阐明其真实涵义. 本文在对贵州荔波董哥洞 ${ }^{[10,13,14]}$ 附
近的凉风洞(LFD)(董哥洞东南约 $8 \mathrm{~km}$ )进行一系列前 期试验研究基础上, 如试验示踪研究等 ${ }^{[18]}$, 通过对其 洞穴系统进行监测和采样分析, 试图利用当地大气 降水、土壤水、滴水及其对应的次生化学沉积物氧(氢) 同位素组成, 剖析洞穴系统中氧同位素的演化和信 息传递过程，探讨其对古气候研究的指示意义.

\section{1 研究区域概况、样品采集及分析测试} 方法

凉风洞位于贵州省荔波县洞塘乡尧所村, 基本情 况见图 1 和表 1. 该区大气降雨主要发生在 5 9 月(雨 季), 10 月 次年 4 月(旱季)降水量较少, 约占全年的 $14 \%$. 所采样品主要包括大气降水、土壤气(采样方法 详见黎廷宇等人 ${ }^{[20]}$ )、土壤水、洞穴滴水及其对应次 生化学沉积物(表面皿收集, 始于 2003 年 6 月, 2004 年 6 月取回). 其中, 大气降水随机采集于 2003 年 4 9 月和 2004 年 3 5 月, 共计 14 个样品; 土壤气和洞穴 滴水分别于 2003 年 4, 6, 7, 8, 9, 10 月和 2004 年 $3,4,5$ 


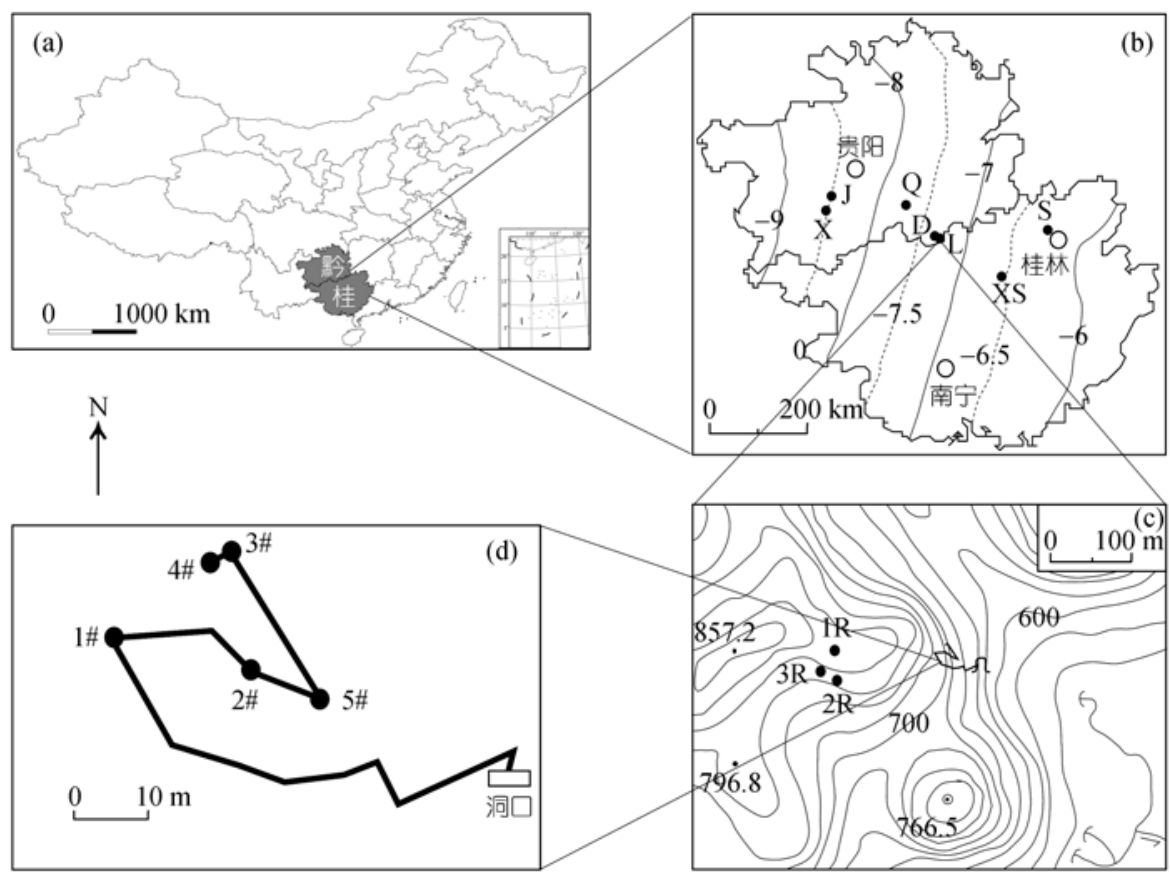

图 1

(a), (b) 洞穴地理位置, (b) 平均大气降水 $\delta^{18} \mathrm{O}$ 分布, 方法详见文献[19]; (c) 地形; (c), (d) 洞穴走向和采样点位置示意图. (b)中 $\mathrm{Q}, \mathrm{L}, \mathrm{J}, \mathrm{X}, \mathrm{D}, \mathrm{S}, \mathrm{XS}$ 分别代表七星洞、凉风洞、将军洞、犀牛洞、董哥洞、水南洞、响水岩洞. 一, 洞穴位置; $\bigcirc$, 城市; 图(c) 和(d)中 $R$ 为土壤水和土壤气点; $\#$, 滴水点

表 1 凉风洞洞穴系统的基本概况 ${ }^{\text {a) }}$

\begin{tabular}{cccccccc}
\hline 洞穴位置 & 经度 & 纬度 & 洞口海拔 $/ \mathrm{m}$ & 洞穴地层 & 植被类型 & 土壤厚 $/ \mathrm{cm}$ & 土被 \\
\hline 荔波洞塘 & $108^{\circ} 03^{\prime} \mathrm{E}$ & $25^{\circ} 16^{\prime} \mathrm{N}$ & 620 & $\mathrm{C}_{2+3}$ 灰岩 & 原生性森林 & $27(5 \sim 135)$ & 不连续 \\
\hline \hline 土壤质地 & 土孔隙度 & 顶板厚度 $/ \mathrm{m}$ & $\mathrm{MAT} /{ }^{\circ} \mathrm{C}$ & $\mathrm{MAP} / \mathrm{mm}$ & $\mathrm{MAH}(\%)$ & 洞温度/ ${ }^{\circ} \mathrm{C} *$ & 洞湿度 $(\%)^{*}$ \\
\hline 壤质 & 中 & $80 ~ 140$ & 18.6 & 1004.1 & $77.5 \pm 3.2$ & $15.1 \pm 1.3$ & $98 \pm 2$ \\
\hline
\end{tabular}

a) MAT(年均气温)、MAP(年均降水量)和 $\mathrm{MAH}$ (年均空气相对湿度)均为 2004 年当地气象站年平均值; ${ }^{*}, 1$ \#滴水点附近的 9 次实测(与滴水 的采集时间一致)数据平均值

月共收集 9 次; 土壤水采集时间与土壤气等一致. 所采 集水样均密封于塑料管中低温(约 $\left.4^{\circ} \mathrm{C}\right)$ 保存. 5 个滴水采 样点集中分布在主通道层中(图 1(d)). 3 组地表采样点 (土壤水和土壤气等)均大致分布于洞穴上方(图 1(c)).

水和沉积物氧(氢)同位素直接用连续流质谱仪 IsoPrime 测试. 氧(氢)同位素数据均采用 SMOW(水样) 和 PDB(沉积物)表示, 单位为 $\%$, 氢、氧同位素测定误差 分别小于 $5 \%$ 和 $0.1 \%$. $\mathrm{CO}_{2}$ 氧同位素用 MAT- 252 测试, 精度为 $0.03 \%$. 所有测试工作均在中国科学院地球化 学研究所环境地球化学国家重点实验室完成.

\section{2 结果与讨论}

2.1 大气降水、土壤水和滴水氢氧同位素组成与 LMWL

大气降水、土壤水和滴水氢氧同位素之间的关系
如图 2 所示. 总体上, 3 种水都分布在IAEA桂林站大 气降水线LMWL上或附近 (由于对LFD地区大气降水 样的采集不够系统, 不能较好地构筑LMWL, 选用与 LFD距离较近的IAEA桂林数据 ${ }^{[21]}$ 代替). 这表明,

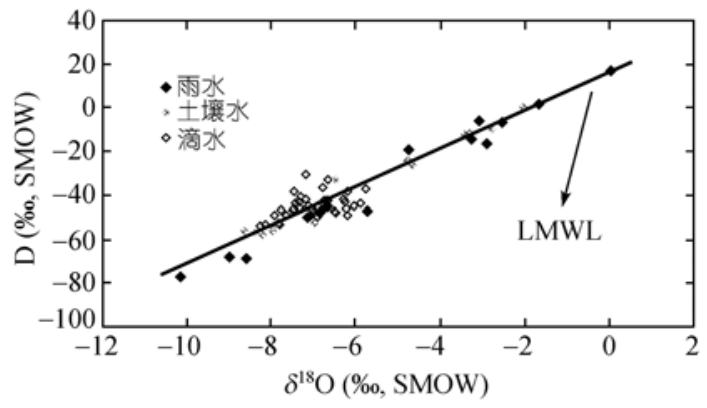

图 2 LFD大气降水、土壤水和滴水氢氧同位素组成与

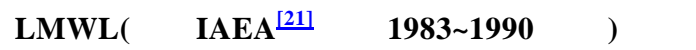


一方面, 大气降水可能是 LFD 土壤水和滴水的重要 来源, 另一方面, 部分土壤水和滴水同位素值轻微偏 向于 LMWL 右下方, 显示蒸发作用对这两种水的同 位素组成有轻微影响. 图 2 还显示, 从大气降水到土 壤水和滴水, 氢氧同位素值的变化幅度逐渐减小, 详 见 2.2 节的论述.

\section{2 大气降水-土壤水-滴水氧同位素信号传递}

喀斯特洞穴次生化学沉积物形成过程如下:

$$
\begin{aligned}
& \mathrm{H}_{2} \mathrm{O}+\mathrm{CO}_{2} \rightleftharpoons \mathrm{H}^{+}+\mathrm{HCO}_{3}^{-} \\
& \mathrm{H}^{+}+\mathrm{CaCO}_{3} \rightleftharpoons \mathrm{Ca}^{2+}+\mathrm{HCO}_{3}^{-} \\
& \mathrm{Ca}^{2+}+2 \mathrm{HCO}_{3}^{-} \rightleftharpoons \mathrm{CaCO}_{3} \downarrow+\mathrm{CO}_{2} \uparrow+\mathrm{H}_{2} \mathrm{O}
\end{aligned}
$$

在这些过程中氧同位素交换是否平衡将直接影 响同位素信号的传递. 文中先检验土壤 $\mathrm{CO}_{2}$ 与土壤水 之间是否达到氧同位素平衡(关于水-岩平衡的讨论 与计算见表 2 和 2.3 节). 检验结果(图 3)显示, 实测值 (土壤水平均 $\delta^{18} \mathrm{O}$ 值) 与根据土壤 $\mathrm{CO}_{2}$ 的 $\delta^{18} \mathrm{O}$ 实测值 $\left(10 \mathrm{~cm}\right.$ 以下平均 $\delta^{18} \mathrm{O}$ 值)计算所得的与之平衡的土壤 水 $\delta^{18} \mathrm{O}$ 理论值基本上是一致的, 表明在LFD上覆土 壤中 $\mathrm{CO}_{2}$ 与入渗水之间的氧同位素交换过程达到或 接近同位素平衡, 即从大气降水到滴水过程中, 氧同 位素信号在土壤带中的传递过程不会导致同位素信 号的失真. 实际上, 根据 Hesterberg等人 ${ }^{[23]} 1988$ 1989 两年的定点观测, 发现土壤 $\mathrm{CO}_{2}$ 的 $\delta^{18} \mathrm{O}$ 值无论 年内还是年际变化均与土壤水的 $\delta^{18} \mathrm{O}$ 值变化一致, 即二者之间的氧同位素交换是平衡的, 其他学者也 得出相似的结论

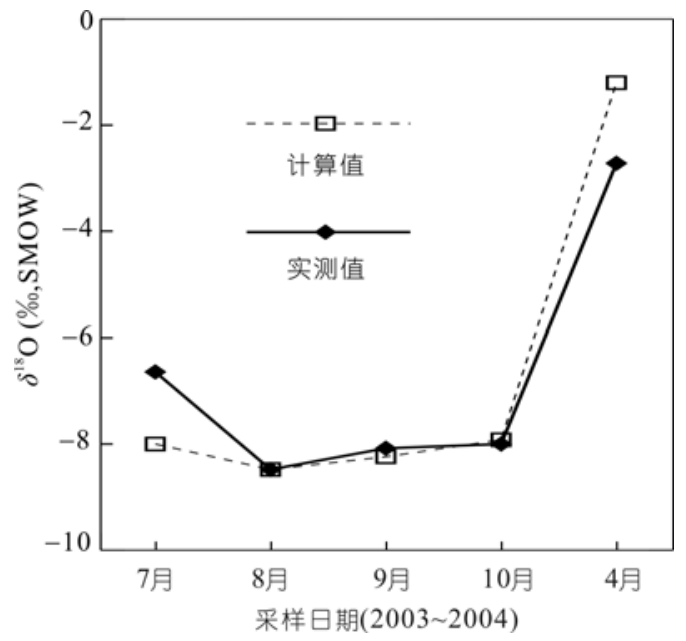

图 3 实测土壤水平均 $\delta^{18} \mathrm{O}$ 值与通过土壤 $\mathrm{CO}_{2}$ 的 $\delta^{18} \mathrm{O}$ 平 衡计算所得的土壤水 $\delta^{18} \mathrm{O}$ 理论值比较

$\delta^{18} \mathrm{O}_{\text {soil- } \mathrm{H}_{2} \mathrm{O}}=\delta^{18} \mathrm{O}_{\text {soil-CO }}-\left(16.60 \cdot 10^{3} / T-15.69\right)^{[22]}$
从图 4 可见, 大气降水、土壤水 $(50$ 和 $100 \mathrm{~cm})$ 和滴水 3 种水的氧同位素值在雨季都出现偏负特征, 旱季呈现偏正特征, 3 者均存在大致协调的同步变化 关系, 且 3 种水同位素值的变化幅度在年内依次显著 减小, 分别在 $0 \sim-10 \%$ 、 $-2 \%$ - $9 \%$ (50 和 $100 \mathrm{~cm}$ 分 别为 $-2.0 \%$ o $-9.3 \%$ 和 $-2.7 \%$ $\sim-8.3 \%$ ) 和 $-6 \%$ $\sim-8 \%$ o 之间. 这种现象可能是不同期次水混合所致, 即均质 化(homogenization)过程, 但这种均质化过程并不完 全 ${ }^{[25,27,28]}$, 即土壤水和滴水氧同位素值的季节变化都 没有消失. 尽管土壤水和滴水均主要来源于大气降 水, 但两者都不大可能来源于单独的某一次, 甚至某 一时段降水, 更可能是不同场次降水, 甚至是不同月 份或季节降水的混合物, 而这种变化幅度减小的程 度取决于与水流运移机制有关的混合过程的效率和 频率 ${ }^{[25]}$, 因此, 像LFD这种温暖潮湿的地区, 从大气 降水到洞穴滴水, 变化幅度逐渐减小, 以至于地下水 同位素组成可能与当地平均大气降水同位素值相近 [29]. 这些现象显示出, 大气降水氧同位素的季节变化 信号被大致同步地传递到了洞穴滴水中, 其过程可 能是: 氧同位素季节变化极为显著的大气降水降落 于地表 $\rightarrow$ 渗入土壤层, 发生一定程度新-老水的混合 和蒸发作用 $\rightarrow$ 通过基岩缝隙或管道进入洞穴形成滴 水, 在此过程中新-老水的混合作用更加明显 $\rightarrow$ 最终 沉积于次生化学沉积物中.

图 1(b)显示, LFD 大气降水 $\delta^{18} \mathrm{O}$ 降水量加权年 均值约为 $-7.3 \%, 50$ 和 $100 \mathrm{~cm}$ 土壤水算术平均值分 别约为 $-5.9 \%$ 和 $-6.4 \%$, 而滴水 $\delta{ }^{18} \mathrm{O}$ 算术平均值约 为 $-7.0 \%$ (年均值可能还会稍微偏重些, 因为缺乏 11 2 月观测数据). 这表明, 3 种水平均氧同位素值相 比较, 大气降水最轻, 土壤水最重, 滴水介于其中. 理论上, 如果从地表大气降水到洞穴滴水的过程中 没有受到外源和蒸发作用的影响, 滴水 $\delta^{18} \mathrm{O}$ 算术平 均值应该与大气降水 $\delta^{18} \mathrm{O}$ 降水量加权年均值相近. 结合上一段关于 3 种水同位素值的变化幅度在年内 依次显著减小现象的讨论, 说明滴水没有完全继承 土壤水和/或大气降水的同位素信息, 一方面, 可能 与洞穴系统包气带含水层的结构和功能有关. 图 4 显 示, 滴水氧同位素值更加接近雨季的大气降水同位 素值, 表明雨季降水对滴水的贡献是主要的, 洞穴系 统包气带含水层对滴水存在着显著的调蓄作用. 另 一方面, 滴水 $\delta^{18} \mathrm{O}$ 算术平均值相对大气降水偏重 $0.3 \%$ 以上, 是由地表蒸发作用引起的. 这是由于在 


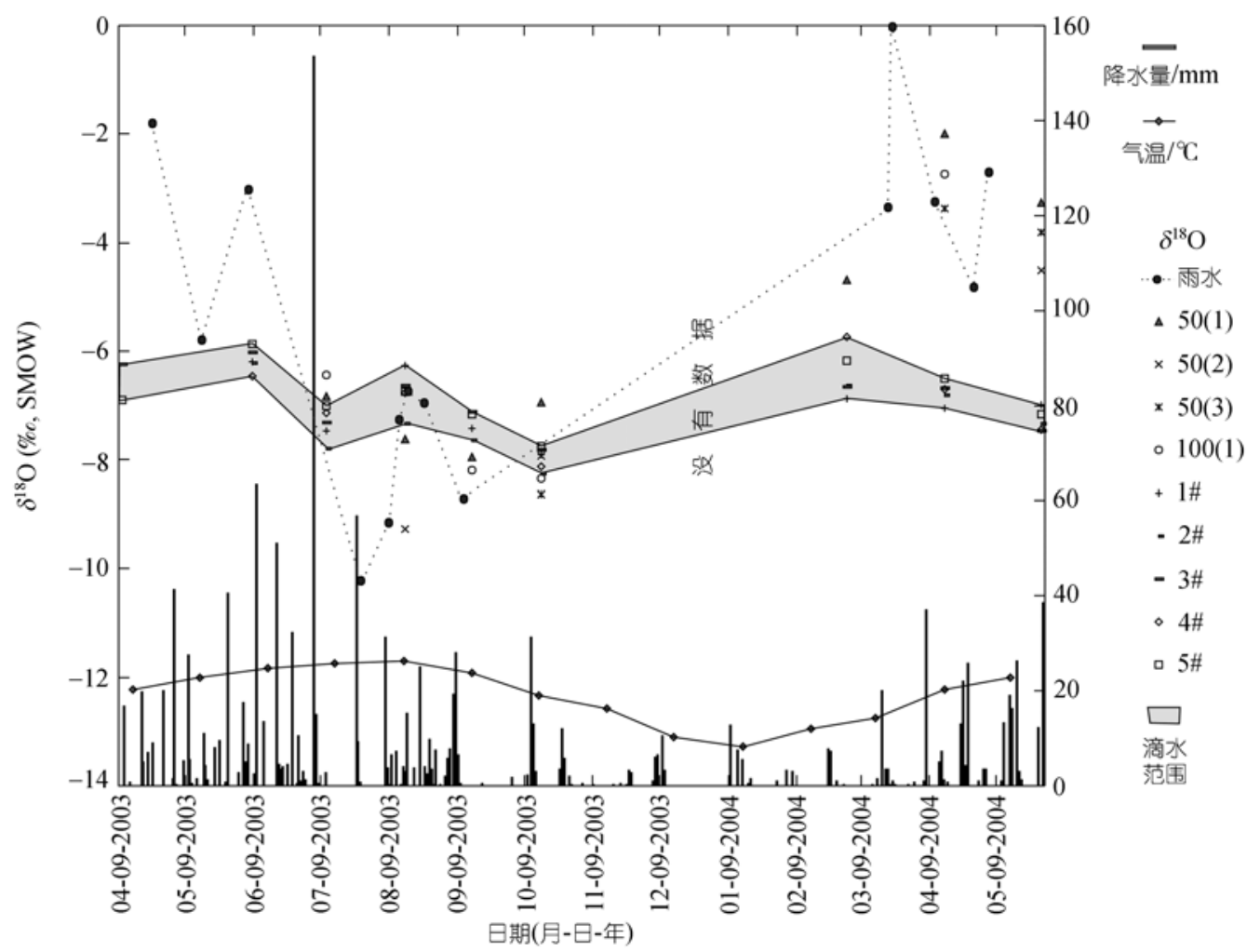

图 4 大气降水、土壤水和洞穴滴水氧同位素组成与当地日降水量和月均气温的季节变化

数据来自当地气象站; 50(1)、1 \# 分别指 1 号点 $50 \mathrm{~cm}$ 深土壤水和 1 号滴水, 其他依此类推. 所有月平均数据均投到当月的第 15 日上

表 2 洞穴滴水和相应次生沉积物的氧同位素组成(水为 SMOW, 沉积物为 PDB, \%o)及计算温度 a)

\begin{tabular}{|c|c|c|c|c|c|c|c|c|c|c|c|c|}
\hline \multirow{2}{*}{ 滴水点编号 } & \multicolumn{9}{|c|}{ 采样日期 2003 2004 年(月-日) } & \multirow{2}{*}{ 滴水算术平均 } & \multirow{2}{*}{ 沉积物 } & \multirow{2}{*}{ 计算温度 $/{ }^{\circ} \mathrm{C}^{*}$} \\
\hline & $04-10$ & 06-08 & $07-11$ & $08-16$ & $09-15$ & $10-16$ & 03-02 & $04-15$ & $05-29$ & & & \\
\hline $1 \#$ & - & -6.2 & -7.5 & -6.3 & -7.4 & -7.9 & -6.9 & -7.0 & -7.0 & $-7.0 \pm 0.6$ & -6.7 & 14.4 \\
\hline $2 \#$ & - & -6.2 & -7.8 & -7.3 & -7.6 & -8.3 & -6.6 & -6.8 & -7.3 & $-7.3 \pm 0.7$ & -6.7 & 13.1 \\
\hline $3 \#$ & -6.2 & -6.0 & -7.3 & -6.8 & -7.1 & -7.8 & -6.7 & -6.7 & -7.5 & $-6.9 \pm 0.6$ & -6.8 & 15.2 \\
\hline $4 \#$ & - & -6.5 & -7.2 & -6.8 & - & -8.1 & -5.7 & -6.7 & -7.5 & $-6.9 \pm 0.8$ & -7.0 & 16.1 \\
\hline $5 \#$ & -6.9 & -5.9 & -7.0 & -6.8 & -7.2 & -7.8 & -6.2 & -6.5 & -7.2 & $-6.8 \pm 0.6$ & -6.7 & 15.2 \\
\hline
\end{tabular}

a) -表示没数据; ${ }^{*}, 10^{3} \ln \alpha_{\text {岩-水 }}=2.78\left(10^{6} T^{-2}\right)-2.89^{[35]}$

洞穴次生化学沉积物形成过程(方程(1) (3))中，来自 基岩 $\left(\mathrm{CaCO}_{3}\right)$ 溶解和 $\mathrm{CO}_{2}$ 水化和逃逸的氧质量数相对 于水中的氧质量数是非常微量的, 故基岩和 $\mathrm{CO}_{2}$ 对沉 积物(滴水)氧同位素的影响是可以忽略的, 且滴水主 要来源于当地降雨(图 2 和 4), 因此, 滴水相对于大气 降水的偏重是由地表蒸发所致, 其调节程度 $\geq 0.3 \%$.

前人研究 ${ }^{[30 \sim 32]}$ 表明, 地表蒸发作用强度随着土 壤深度的增加呈指数下降趋势, 其影响作用一般都 在数厘米范围内, 尤其是对于像空气相对湿度较大 $(77.5 \% \pm 3.2 \%)$ 、植被茂密的LFD这样的地区，地表蒸 发作用很弱 ${ }^{[33]}$; 同时，在中国南方喀斯特山区，如 LFD，上覆岩石裂隙发育，土壤质地为壤质，土被不
连续, 有利于水的下渗. 因此，在研究地区，地表蒸 发作用对滴水的影响是有限的(图 2). 另外，图 4 也显 示出这样的特征, 即不论是旱季还是雨季, 土壤水氧 同位素值均与大气降水接近，说明研究地区地表蒸 发作用不显著. 地表蒸发对滴水氧同位素值的影响 作用，与干旱或/和半干旱地区，如东地中海地区约 $1.0 \% \sim 1.5 \%$ 以上上 ${ }^{[17,34]}$ 相比较，不是特别明显.

\section{3 对古气候研究的意义}

5 个滴水点滴水对应次生化学沉积物氧同位素 组成与相应平均滴水相似, 即不同点间的氧同位素

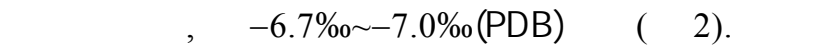


结果表明, 该洞穴所有研究点基本上都达到或接近 同位素平衡(实测洞穴气温在 $12.0 \sim 16.2^{\circ} \mathrm{C}$ 之间, 平均 为 $(15.1 \pm 1.3)^{\circ} \mathrm{C}(n=9)$, 与计算所得温度基本一致)(表 2), 也即通过洞穴次生化学沉积物和其包裹体中水的 氧同位素值计算洞穴气温(也即 MAT)是可行的. 另 外, 图 4 中大气降水-土壤水-滴水氧同位素组成均显 示出与降水量大致协调同步的季节变化关系, 也即 在雨季都出现偏负特征，旱季都呈现偏正特征，表明 在高分辨率(如季节)的古气候研究中, 洞穴次生化学 沉积物氧同位素值的高低指示着当地大气降水量大 小(反相关关系); 而 3 种水同位素值的变化幅度在年 内依次显著减小的现象说明, 在一定条件下, 随着洞 穴上覆介质厚度的增加, 氧同位素受均值化的程度 将会越高, 因此，对于利用洞穴次生化学沉积物氧同 位素值重建高分辨率的古气候研究来说, 可能滴水 对大气降水响应较快或上覆介质相对较薄的洞穴较 为理想.

尽管上述分析显示，在 LFD 这种温暖潮湿气候 下地表蒸发对滴水氧同位素值的影响不大，但通过 同样方法计算与本研究区处于同一气候区域(贵州省) 的其他 3 个洞穴(七星洞、将军洞和犀牛洞)(图 1(b)) 地表蒸发对滴水的影响发现, 3 个洞穴系统中地表蒸 发对滴水的调节程度分别约为 $\geq 0.9 \%, \geq 0.3 \%$ 和 $\geq$ $0.6 \%$ ，表明在相似的气候条件下，不同洞穴之间存
在较大差异. 4 个洞穴系统中, 七星洞和犀牛洞与 LFD不同, 而将军洞与LFD相似 ${ }^{[36]}$. 前 2 个洞穴上覆 土被相对连续, 土壤质地黏重、土层紧实、孔隙度小, 基岩裂隙不发育等, 不利于大气降水向洞穴系统包 气带含水层的快速渗透, 这在前期的实验示踪研究 中也得到证实: 七星洞和犀牛洞对大气降水的响应 时间明显滞后于将军洞与LFD ${ }^{[18]}$. 因此, 地表蒸发作 用对滴水氧同位素值的调节程度除与气候条件相关 外, 与洞穴上覆介质性质也密切相关. 在利用次生化 学沉积物氧同位素指标恢复和重建古气候或者进行 相互对比研究时, 有必要考虑该影响因素.

\section{3 结论}

综上所述, 研究洞穴的次生化学沉积物形成过 程中的氧同位素交换基本上是平衡的; 土壤水和滴 水主要来源于当地大气降水; 3 种水 (大气降水、土壤 水和滴水)氧同位素值的变化幅度在年内依次减小, 分别在 $0 \sim-10 \%$ 、 $-2 \% \%_{0} \sim-9 \%$ 和 $-6 \%{ }_{0} \sim-8 \%$ 之间; 3 种 水氧同位素值之间存在大致协调同步的季节变化规 律: 雨季偏轻，旱季偏重; 地表蒸发作用导致滴水氧 同位素年算术平均值相对于大气降水值偏重约 $0.3 \%$ 以上. 但地表蒸发作用对滴水氧同位素值的调节作 用, 不仅与气候条件密切相关, 还与洞穴上覆介质性 质密切相关.

致谢 感谢周运超教授、黎廷宇博士、谢兴能博士和程安云博士在野外采样和室内分析给予的协助, 同时对荔波茂兰国家 级自然保护区管理局给予的支持表示诚挚谢意, 尤其感谢评审专家给予的建设性意见.

\section{参考文献}

1 Hendy C H, Wilson A T. Paleoclimate data from speleothem. Nature, 1968, 219(5149): 48 - 51

2 Duplessey J C, Labeyric J, Lalou C, et al. Continental climatic variations between 130000 and 90000 years B.P. Nature, 1970, 226: 631633

3 Hendy C H. The isotopic geochemistry of speleothems I. The calculation of the effects of different modes of formation on the isotopic composition of speleothems and their applicability as palaeoclimatic indicators. Geochim Cosmochim Acta, 1971, 35(8): 801824

4 Treble P C, Schmitt A K, Edwards R L, et al. High resolution Secondary Ionisation Mass Spectrometry (SIMS) $\delta^{18} \mathrm{O}$ analyses of Hulu Cave speleothem at the time of Heinrich Event 1. Chem Geol, 2007, 238(3-4): 197-212[DOI]

5 蔡演军, 彭子成, 安芷生, 等. 贵州七星洞全新世石笋的氧同位素记录及其指示的季风气侯变化. 科学通报, 2001, 46(16): 1398-1402

6 Wang Y J, Cheng H, Edwards R L, et al. A high-resolution absolute dated late Pleistocene monsoon record from Hulu Cave, China. Science, 2001, 294(5550): 2345-2348[DOI]

7 何尧启, 汪永进, 孔兴功，等。贵州董哥洞近 $1000 \mathrm{a}$ 来高分辨率洞穴石笋 $\delta^{18} \mathrm{O}$ 记录. 科学通报, 2005, 50(11): 1113-1118

8 郡晓华, 汪永进, 程海, 等. 全新世季风气候演化与千旱事件的湖北神农架石笋记录. 科学通报, 2006, 51(1): 80-86 
9 Fairchild I J, Tuckwell G W, Baker A, et al. Modelling of dripwater hydrology and hydrogeochemistry in a weakly karstified aquifer (Bath, UK): Implications for climate change studies. J Hydrol, 2006, 321(1-4): 213-231 [DOI]

10 Yuan D X, Cheng H, Edwards R L, et al. Timing, duration, and transition of the last interglacial Asian Monsoon. Science, 2004, 304(5670): 575-578 $\underline{\text { DOI] }}$

11 Baker A, Asrat A, Fairchild I J, et al. Analysis of the climate signal contained within $\delta^{18} \mathrm{O}$ and growth rate parameters in two Ethiopian stalagmites. Geochim Cosmochim Acta, 2007, 71(12): 2975-2988 [DOI]

12 Zhang M, Yuan D, Lin Y, et al. A 6000-year high-resolution climatic record from a stalagmite in Xiangshui cave, Guilin, China. Holocene, 2004, 14(5): 697-702[DOI]

13 张美良, 林玉石, 覃嘉铭, 等. 黔南洞穴石笋古气候变化记录及终止点 II 的确定. 中国科学 D 辑: 地球科学, 2002, 32(11): 942950

14 Wang Y J, Cheng H, Edwards R L, et al. The Holocene Asia monsoon: Links to solar changes and North Atlantic climate. Science, 2005, 308(5723): 854-857 $\underline{\text { DOI] }}$

15 Wang Y J, Cheng H, Edwards R L, et al. Millennial- and orbital-scale changes in the East Asian monsoon over the past 224000 years. Nature, 2008, 451(7182): 1090-1093[DOI]

16 李涁, 袁道先, 林玉石, 等. 桂林地区降水、洞穴滴水及现代洞穴碳酸盐氧碳同位素研究及其环境意义. 中国科学 D 辑: 地 球科学, 2000, 30(1): 81-87

17 Bar-Matthews M, Ayalon A, Matthews A, et al. Carbon and oxygen isotope study of the active water-carbonate system in a karstic Mediterranean cave: Implications for paleoclimate research in semi-arid regions. Geochim Cosmochim Acta, 1996, 60(2): 337-347 [DOD]

周运超, 王世杰, 谢兴能, 等. 贵州 4 个洞穴滴水对大气降雨响应的动力学及其意义. 科学通报, 2004, 49(21): 2220-2227

罗维均, 王世杰, 刘秀明. 中国大气降水 $\delta^{18} \mathrm{O}$ 区域特征及其对古气候研究的意义. 地球与环境, 2008, 36(1): 47一 55

黎廷宇, 王世杰, 郑乐平. 黔中碳酸盐岩和非碳酸盐岩上覆土壤 $\mathrm{CO}_{2}$ 来源的对比研究. 中国科学 D 辑: 地球科学, 2001, 31(9): $777-782$

IAEA/WMO. Global Network of Isotopes in Precipitation. In: The GNIP Database, 2004

Hesterberg R, Siegenthaler. Production and stable isotopic composition of $\mathrm{CO}_{2}$ in a soil near Bern, Switzerland. Tellus, 1991, 43B(2): $197-205$

Brenninkmeijer C A M, Kraft P, Mook W G. Oxygen isotope fractionation between $\mathrm{CO}_{2}$ and $\mathrm{H}_{2} \mathrm{O}$. Isotope Geosci, 1983, 1(2): 181190

Tang K, Feng X. The effect of soil hydrology on the oxygen and hydrogen isotopic compositions of plants' source water. Earth Planet Sci Lett, 2001, 185(3-4): 355-367 [DOD]

KapilutoY, Yakir D, Tans P, et al. Experimental and numerical studies of the ${ }^{18} \mathrm{O}$ exchange between $\mathrm{CO}_{2}$ and water in the atmosphere-soil invasion flux. Geochim Cosmochim Acta, 2007, 71(11): 2657-2671 [DO]

Cruz Jr F W, Karmann I, Viana Jr O, et al. Stable isotope study of cave percolation waters in subtropical Brazil: Implications for paleoclimate inferences from speleothems. Chem Geol, 2005, 220(3-4): 245-262[DOI]

van Beynen P, Febbroriello P. Seasonal isotopic variability of precipitation and cave drip water at Indian Oven Cave, New York. Hydrol Process, 2006, 20(8): 1793-1803[DOI]

Gat J R. Comments on stable isotope method in regional groundwater investigations. Water Resour Res, 1971, 7(4): 980 -993

蔡树英, 张瑜芳. 温度影响下土壤水分蒸发的数值分析. 水利学报, 1991, (11): 1-8

Gowing J W, Konukcu F, Rose D A. Evaporative flux from a shallow watertable: The influence of a vapour-liquid phase transition. J Hydrol, 2006, 321(1-4): 77-89 [DOD]

Shurbaji A-R M, Phillips F M, Campbell A R, et al. Application of a numerical model for simulating water flow, isotope transport, and heat transfer in the unsaturated zone. J Hydrol, 1995, 171(1-2): 143-163 [DOI]

33 Yamanaka T, Inoue M, Kaihotsu I. Effects of gravel mulch on water vapor transfer above and below the soil surface. Agr Water Manage, 2004, 67(2): 145-155 [DOD

34 Ayalon A, Bar-Matthews M, Sass E. Rainfall-recharge relationships within a karstic terrain in the Eastern Mediterranean semi-arid region, Israel: $\delta^{18} \mathrm{O}$ and $\delta$ D characteristics. J Hydrol, 1998, 207(1-2): 18-31 [DOI]

35 Friedman I, O’Neil J R. Compilation of stable isotope fractionation factors of geochemical interest. In: Fleischer M, ed. Data of Geochemistry. 6th ed. US Geol Surv Prof Paper, 1977, KK1-KK12

36 罗维均. 喀斯特洞穴系统中稳定同位素地球化学特征及其环境意义. 博士学位论文. 贵阳: 中国科学院地球化学研究所, 2007. 17-17 